\title{
Anion selective optical sensing with metalloporphyrin-doped polymeric films
}

\author{
Enju Wang and Mark E. Meyerhoff \\ Department of Chemistry, The University of Michigan, Ann Arbor, MI 48109 (USA)
}

(Received 27th April 1993; revised manuscript received 28th June 1993)

\begin{abstract}
Metalloporphyrins [Mn(III) and In(III)] are investigated as active polymer film components in the design of reversible anion-selective optical sensors. The optical measurements are made by casting thin plasticized polymer films (PVC, polyurethane, etc.) containing the given metalloporphyrins on glass plates. When bathed in aqueous test solutions, the optical response of such films is based upon the selective extraction of anions by metalloporphyrins into the organic membrane phase. Changes in optical absorbance occur via either of two mechanisms. For films based on Mn(III) tetraphenylporphyrins, the porphyrin itself can serve simultaneously as the ionophore and chromophore for the detection of iodide ions. In this instance, direct ligation of iodide as an axial ligand of the central Mn(III) results in a change in the molar absorptivity of the soret band of the porphyrin. In the case of In(III) octaethylporphyrin, the incorporation of an appropriate $\mathrm{pH}$-indicator dye along with the metalloporphyrin is required to achieve films with optical selectivity toward nitrite and chloride. The analytical characteristics of these porphyrin-based films with respect to anion response time, dynamic measurement range, and reproducibility, are discussed.
\end{abstract}

Keywords: Sensors; Anion selectivity; Optical sensing; Polymeric films; Metalloporphyrins

The intrinsic properties of optical sensors has led to their suggested use in a wide range of analytical applications [1,2]. While many of the earliest optical sensors developed for detecting cations and neutral species (e.g., gases) were based on immobilizing chemically sensitive components on the surface of solid supports (e.g., glass fibers, silica particles, etc.) [3-6], limitations of these systems including poor reversibility, selectivity and stability has prompted newer approaches. In recent years, a large number of ionophores used previously in the design of potentiometric ion-selective organic membrane electrodes have been adapted to design optical cation $\left(\mathrm{M}^{+}\right)$sensing systems $[7,8]$. In these sens-

Correspondence to: M.E. Meyerhoff, Department of Chemistry, The University of Michigan, Ann Arbor, MI 48109 (USA). ing schemes, the ionophores are doped, along with appropriate $\mathrm{pH}$ indicator dyes, into thin $(<10 \mu \mathrm{m})$ polymeric films. When bathed in a sample solution, simultaneous $\mathrm{H}^{+} / \mathrm{M}^{+}$ion exchange equilibria occur between the two phases, resulting in a change in the optical absorbance of the film. Using this approach, highly selective optical sensing films for $\mathrm{NH}_{4}^{+}$[9], $\mathrm{Ca}^{2+}[10], \mathrm{K}^{+}$ [11], $\mathrm{Na}^{+}[12]$ and $\mathrm{Pb}^{2+}[13]$ have been prepared.

Adopting this same ionophore/pH indicator approach to design optical anion sensors is, however, far more challenging. Indeed, there are relatively few anion selective ionophores that have been used successfully in previous polymer membrane type ion-selective electrodes. Recently, optical sensors for nitrate and chloride have been suggested based on polymer films doped with quaternary ammonium exchangers [14] and organic tin compounds [15], respectively. However, 
those based on quaternary ammonium exchangers always display Hofmeister type selectivity, with the largest response to lipophilic anions (e.g., perchlorate, thiocyanate, etc.). Behringer et al. [16] have used a chromophoric derivative of a known carbonate selective ionophore (based on reaction of carbonate with trifluoroacetophenone species) along with a lipophilic quaternary ammonium species within a thin polymeric film to devise a highly selective carbonate optical sensor. Alternate schemes for optical anion sensing have also been proposed, including sensors for halide ions based on direct quenching of fluorescence of acridinium or quinolinium immobilized on a glass surface via spacer groups $[17,18]$, and cyanide/ nitrite based on vitamin $B_{12}$ derivatives dissolved in an organic solution trapped in contact with an optical fiber behind a gas permeable membrane $[19,20]$. Despite these early efforts, achieving novel anion selectivities in optical sensor technology remains a challenge.

We have previously demonstrated that when certain metalloporphyrins are used as carriers in polymeric membrane electrodes, the resulting sensors display unique anion responses [21-23]. Specifically, membranes formulated with Mn(III), Sn(IV), and In(III) porphyrins exhibit relatively high potentiometric selectivity toward thiocyanate [21], salicylate [22], and chloride [23], respectively. Such selectivity has been attributed to the preferred interaction of these anions as axial ligands with the metal center of the metalloporphyrin structure. As demonstrated earlier with cobalamin derivatives [20], these anion exchange ligation reactions can also influence the UV-visible absorption bands of the metal-ligand complexes which are potentially. useful in designing optical anion sensors. Alternately, when the selective anion ligation reaction does not alter the absorption spectrum of the metalloporphyrins, incorporation of the porphyrin along with a $\mathrm{pH}$ indicator into an appropriate polymer film can be employed in devising anion selective sensors. In this report, both of these sensing schemes (see Figs. 1 and 2) are demonstrated by using $\mathrm{Mn}$ (III) porphyrins for the direct sensing of iodide and In(III) porphyrins in conjunction with a lipophilic $\mathrm{pH}$ indicator for the reversible detection of chloride and nitrite.

\section{EXPERIMENTAL}

\section{Reagents}

The structures of some representative metalloporphyrins and $\mathrm{pH}$ indicators used in this work are shown in Fig. 1. Octaethylporphyrin (OEP), chloro $(5,10,15,20$-tetraphenylporphyrinato) manganese(III) [Mn(TPP)Cl], chloro(5,10,15,20-tetraphenylporphyrinato) rhodium(III) [Rh(TPP)Cl] and dichloro(5,10,15,20-tetraphenylporphyrinato) $\operatorname{tin}(\mathrm{IV})\left[\mathrm{Sn}(\mathrm{TPP}) \mathrm{Cl}_{2}\right]$ were obtained from Midcentury Chemicals (Posen, IL). Chloro(octaethylporphyrinato) indium(III) [In(OEP)Cl] was synthesized and purified according to the method described previously $[24,25]$. Ortho-nitrophenyl octyl ether (o-NPOE), bis(2-ethylhexyl)sebacate (DOS), 3-hydroxy-4-(4-nitrophenylazo)phenyl octadecanoate (ETH 2412), high molecule weight poly(vinyl chloride) (PVC), and tetrahydrofuran (THF) were obtained from Fluka (Ronkonkoma, NY). Tridodecylmethylammonium chloride (TDMAC or MTDDACl) was from Polyscience

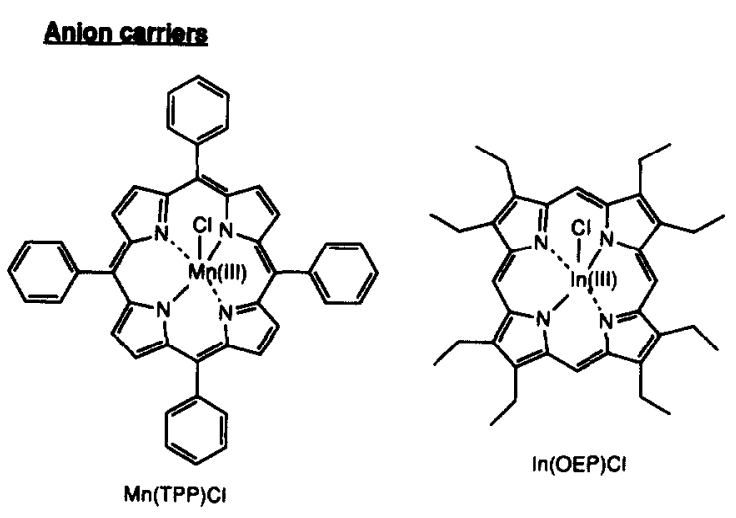

\section{pHindlontors}
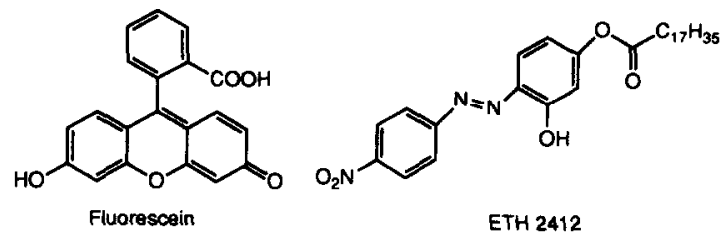

Fig. 1. Structures of some metalloporphyrins and $\mathrm{pH}$ indicators used to preparc anion sensing polymer films. 
(Warrington, PA) and Tecoflex polyurethane (PU, SG-80A) from Thermedics (Woburn, MA). Fluorescein (Fl) was from Aldrich (Milwaukee, WI), while 2-( $N$-morpholino)ethanesulfonic acid (MES) and sodium salicylate were products of Sigma (St. Louis, MO). All other chemicals were commercial reagent grade products. Standard solutions and buffers were prepared with reverse osmosis-deionized water.

\section{Film preparation}

PVC film compositions were similar to that described for ion-selective electrode membranes [21-23] [30 wt.\% of PVC, 1 wt.\% of carrier (metalloporphyrins) and $69 \mathrm{wt} . \%$ of plasticizer (DOS or $o$-NPOE)]. The PVC/PU films were composed of 15 wt.\% of PVC and 15 wt.\% of PU, $1 \mathrm{wt} . \%$ of carrier and $69 \mathrm{wt} . \%$ of plasticizer. Films containing In(OEP) Cl and $\mathrm{pH}$ indicator (either Fl or ETH 2412) were formulated with 2 wt.\% of In(OEP)Cl, 1 wt.\% of indicator, $30 \mathrm{wt} . \%$ of polymer(s), and $67 \mathrm{wt} . \%$ of plasticizer. Blank films used as the reference had the same compositions but without the metalloporphyrin and/or the pH indicator [in the case of the In(III) porphyrin]. The solutions used to cast the optical anion sensing films were made by dissolving a total of $200 \mathrm{mg}$ of membrane components in $2 \mathrm{ml}$ THF. Final films were cast onto the glass slides $(0.9 \times 4 \mathrm{~cm}, 1 \mathrm{~mm}$ in thickness $)$ manually with a pipette or by spin coating at $2000 \mathrm{rpm}$. The resulting films had thicknesses in the range of 3-10 $\mu \mathrm{m}$.

\section{Absorbance measurements}

Optical measurements were made with a UV-visible double beam spectrophotometer (Lambda 3B, Perkin Elmer) with the polymer film coated glass plates placed in a conventional cuvette $\left(1 \times 1 \times 4 \mathrm{~cm}^{3}\right)$ containing the test anion solution. The films were soaked in water or 0.05 $\mathrm{M} \mathrm{NaH}{ }_{2} \mathrm{PO}_{4}(\mathrm{pH} \mathrm{4.2)}$ for 20 min before the first measurements were made. Test solutions were prepared by adding appropriate salts of the test anions to either water, a $0.05 \mathrm{M} \mathrm{NaH}_{2} \mathrm{PO}_{4}(\mathrm{pH}$ 4.2) electrolyte solution, a $0.05 \mathrm{M}$ tris(hydroxyamino)methanesulfuric acid (Tris-SO ${ }_{4}$ ) buffer $(\mathrm{pH}$ 7.2), or a $0.05 \mathrm{M}$ MES buffer (pH 5.5).

\section{RESULTS AND DISCUSSION}

\section{Preliminary studies}

Preliminary experiments involved casting polymer films containing several of the metalloporphyrins known to yield novel anion selectivities in previous potentiometric studies [21-23] [e.g., $\mathrm{Mn}$ (TPP)Cl, In(OEP)Cl, $\mathrm{Sn}$ (TPP) $\left.\mathrm{Cl}_{2}\right]$ and observing changes in the absorption of the films when exposed to test anion solutions at various concentrations in water. Ion-exchange of the initial chloride ligand by other anions (including hydroxide from water) was expected to result in changes in the absorbances of the films. Indeed, upon exposing a PVC film containing $\mathrm{Mn}$ (TPP)Cl to $0.1 \mathrm{M}$ of iodide or, perchlorate solution, a visual color change of the membrane is observed. Changes in absorbance also occurred when In(OEP)Cl in a PVC matrix was exposed to iodide, nitrite and

a) Metalloporphyrins serve as chromoionophore

Ion-exchange

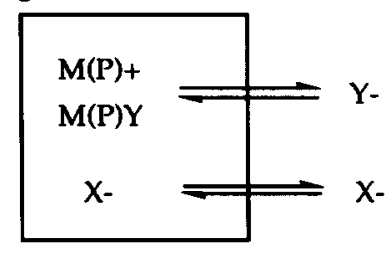

polymer film solution

b) Metalloporphyrins serve as anion ionophore, $\mathrm{pH}$ indicators serve as chromophore.

Ion-coextraction

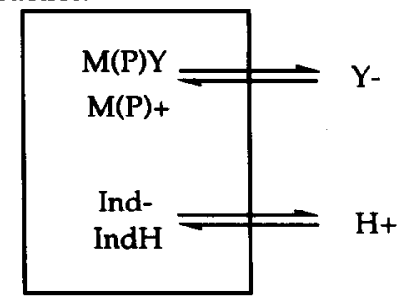

polymer film solution

Fig. 2. Possible optical anion response mechanisms using metalloporphyrins as anion carriers in thin polymeric films; (a) porphyrin as chromophore; (b) added $\mathrm{pH}$ indicator as chromophore. 
chloride, but the absorbance changes were generally much smaller. For $\mathrm{Sn}(\mathrm{TPP}) \mathrm{Cl}_{2}$, and $\mathrm{Rh}(\mathrm{TPP}) \mathrm{Cl}$ doped membranes, iodide and salicylate $\left(\mathrm{Sal}^{-}\right)$caused only slight changes in the intensity of the soret band (around $400 \mathrm{~nm}$ ).

As indicated in Fig. 2a, the direct optical response of metalloporphyrin doped polymer films (without added $\mathrm{pH}$ indicator) may result from selective axial ligand exchange reactions. That is, if the extracted anion $\left(\mathrm{Y}^{-}\right)$can coordinate directly to the metal center of the porphyrin, and this ligation concomitantly alters the electronic structure of the central metal ion, a change in the absorption spectrum will occur. The ligand exchange can either be between an initially ligated anion $\mathrm{X}^{-}$(e.g., $\mathrm{Cl}^{-}, \mathrm{OH}^{-}$) or a neutral ligand such as water. In the latter case, the original anion in the film is not directly ligated to the porphyrin, but serves as a solvated counterion $\left(\mathrm{X}^{-}\right)$to the positively charged porphyrin $-\mathrm{H}_{2} \mathrm{O}$ complex. Thus, using $\mathrm{Mn}$ (III) tetraphenylporphyrin as an example, the two possible reactions that can yield direct optical anion response are as follows:

$$
\begin{gathered}
{[\mathrm{Mn}(\mathrm{TPP}) \mathrm{X}]_{(\mathrm{m})}+\mathrm{Y}_{(\mathrm{aq})}^{-} \rightleftharpoons} \\
{\left[\mathrm{Mn}(\mathrm{TPP}) \mathrm{Y}^{-}\right]_{(\mathrm{m})}+\mathrm{X}_{(\mathrm{aq})}^{-}}
\end{gathered}
$$
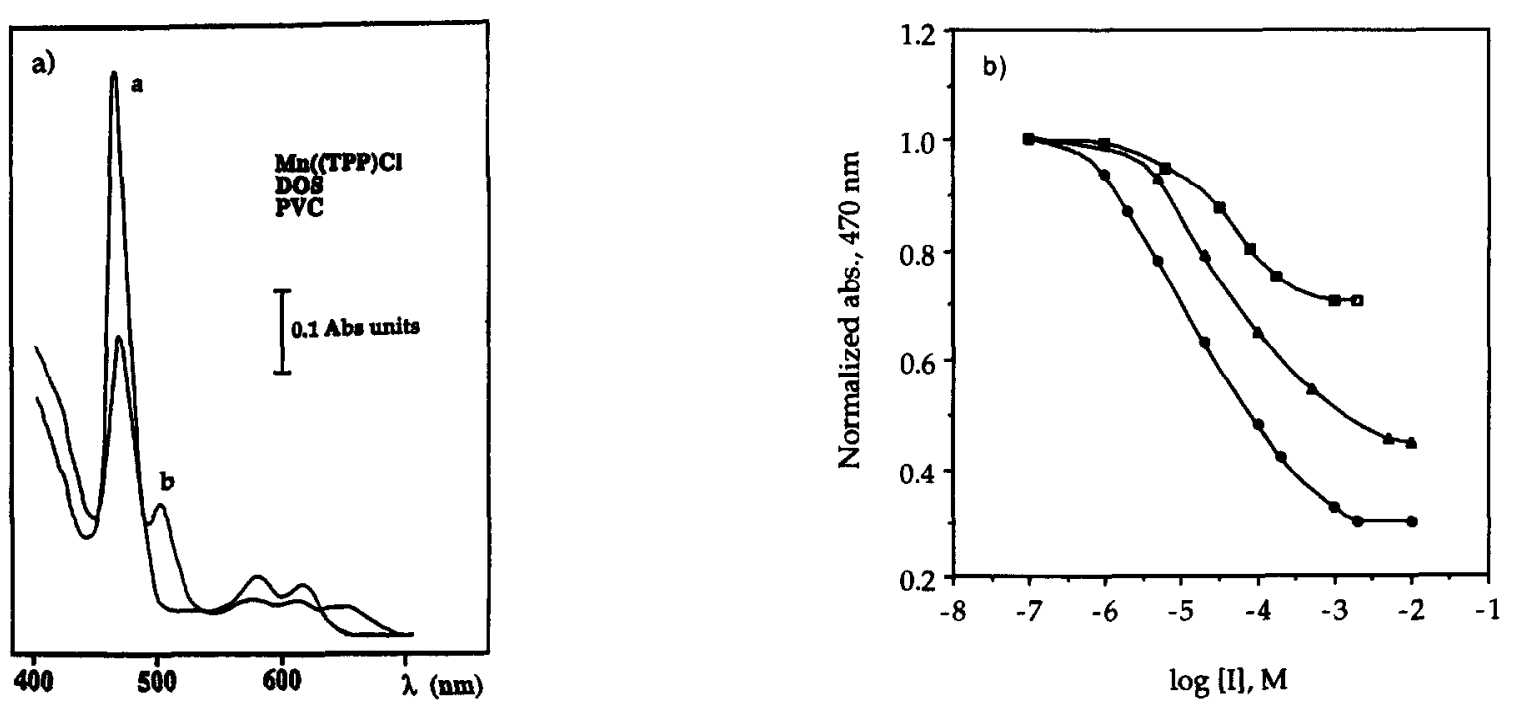

Fig. 3. (a) Absorbance spectra of $\mathrm{Mn}$ (TPP)Cl doped film (PVC/DOS) in solutions with (a) and without (b) iodide ions. (b)

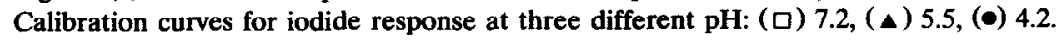

$$
\begin{aligned}
& \text { or } \\
& {\left[\operatorname{Mn}(\mathrm{TPP})\left(\mathrm{H}_{2} \mathrm{O}\right)\right] \mathrm{X}_{(\mathrm{m})}+\mathrm{Y}_{(\mathrm{aq})}^{-} \rightleftharpoons} \\
& {[\mathrm{Mn}(\mathrm{TPP}) \mathrm{Y}]_{(\mathrm{m})}+\mathrm{H}_{2} \mathrm{O}_{(\mathrm{aq})}+\mathrm{X}_{(\mathrm{aq})}^{-}}
\end{aligned}
$$

where $\mathrm{Y}^{-}$is a strong axial ligand for the central $\mathrm{Mn}$ (III) ion of the porphyrin and (m) and (aq) refer to the organic membrane and aqueous sample phases, respectively.

When the original counter anion $\mathrm{X}^{-}$, e.g., chloride, is a relatively weak inner sphere ligand that can readily be displaced by water, and the film is exposed to solutions containing anions that are also a relatively weak ligands $\left(\mathrm{Z}^{-}\right)$, then ion exchange can occur in accordance with following reaction:

$$
\begin{gathered}
{\left[\mathrm{Mn}(\mathrm{TPP})\left(\mathrm{H}_{2} \mathrm{O}\right)\right] \mathrm{Cl}_{(\mathrm{m})}+\mathrm{Z}_{(\mathrm{aq})}^{-} \rightleftharpoons} \\
{\left[\mathrm{Mn}(\mathrm{TPP})\left(\mathrm{H}_{2} \mathrm{O}\right)\right] \mathrm{X}_{(\mathrm{m})}+\mathrm{Z}_{(\mathrm{aq})}^{-}}
\end{gathered}
$$

In this case, since the exchange occurs without displacing the neutral water ligand, it is unlikely that significant changes in the absorption spectrum will occur. Indeed, without direct interaction with the metal center, the equilibrium constant for reaction 3 will be dictated by the relative free energies of hydration of $\mathrm{X}^{-}$ions, and thus, when $\mathrm{X}^{-}$is $\mathrm{ClO}_{4}^{-}$, reaction 3 will be favored. 
Clearly, strong ligands $\left(\mathrm{Y}^{-}\right)$that can replace coordinated water are most likely to yield direct changes in the optical properties of the film. Moreover, the ion exchange equilibrium constant for reactions 1-3 above will ultimately determine the anion selectivities of the membranes doped with the porphyrin structure.

\section{Polymer films with $\mathrm{Mn}(\mathrm{TPP}) \mathrm{Cl}$ for iodide sens- ing}

The polymer films doped with Mn(TPP)Cl yield the largest optical response towards changes in iodide ion levels in the sample. At $470 \mathrm{~nm}$, the $\lambda_{\max }$ for the soret band of $\mathrm{Mn}(\mathrm{TPP}) \mathrm{Cl}$, the changes in absorbance (decrease) toward various anions follow the order: $\mathrm{I}^{-}>\mathrm{NO}_{2}^{-} \gg \mathrm{ClO}_{4}^{-}>$ $\mathrm{Sal}^{-} \sim \mathrm{Cl}^{-} \sim \mathrm{H}_{2} \mathrm{PO}_{4}^{-}$. Figure 3a shows the change in the visible absorption spectrum of a PVC$\mathrm{Mn}$ (TPP)Cl film when exposed to $1 \mathrm{mM}$ pure iodide solution. As shown in Fig. 3b, the optical response of the membrane to iodide in aqueous solutions at different $\mathrm{pH}$ covers a wide range of concentrations, while relatively little change in absorbance is observed when the film is exposed to solutions of chloride, bromide, nitrate, or salicylate. (note: normalized optical response is the absorbance measured for given test solution divided by absorbance in background electrolyte)

The response and recovery times for the $\mathrm{Mn}$ (TPP)Cl doped PVC films toward iodide were examined in detail. For membranes $\sim 5 \mu \mathrm{m}$ thick, the response times range of 3-5 min $\left(t_{95 \%}\right)$, while the recovery time is ca. $10 \mathrm{~min}$. These response and recovery times appear to be dictated by the slow on/off ligand exchange kinetics of the Mn(TPP) species, and the need to maintain charge neutrality in the polymer film. Indeed, when the film is first exposed to a solution of iodide ion followed by exposure to pure water, the latter solution does not have a high enough concentration of anions that can replace the ligated iodide to maintain charge neutrality within the polymer matrix. The recovery time can, however, be reduced to $2 \mathrm{~min}$ by adding salicylate ions to the wash solution; e.g., if the membrane is first exposed to a solution containing salicylate ion for $1 \mathrm{~min}$, then exposed to pure water, the optical signal changes to its original value. It should be noted that the Mn(TPP)Cl doped PVC films maintain their reversible optical iodide response properties for at least 2 weeks, suggesting that Mn(TPP) is stable both optically and chemically in the PVC matrix. The two week limitation for the sensor life-time is due primarily to the partitioning of $\mathrm{Mn}$ (TPP)Cl from the very thin films to the aqueous test solution. Gradual loss of the carrier with time will cause a significant decrease in the absorbance signal necessitating frequent re-calibration. This problem may be minimized by using a more lipophilic Mn(III)porphyrin structure to reduce the partitioning into the aqueous solution [26], thereby enhancing sensor life-time.

Films prepared with a PVC matrix alone exhibit relatively poor adhesion to the surface of glass slides used to test optical anion response of the films. This problem can be overcome by employing a mixture of polyurethane (PU) and PVC as the film matrix. Films composed of plasticized PVC/PU mixtures (15 wt.\% each in film) have comparable life-times and optical properties to those prepared with pure PVC. Moreover, the PVC/PU matrix enables an easier, more reproducible fabrication of a thin, transparent and homogeneous film on the glass substrate, even without using a spin coating device.

The specific plasticizer used within the $\mathrm{Mn}$ (TPP)Cl films has relatively little affect on the optical anion response toward iodide; however, the solubility of $\mathrm{Mn}$ (TPP)Cl as well as other porphyrins in cast films was generally higher when $o$-NPOE rather than DOS was used as the plasticizer.

Although relatively little optical response is observed when the $\mathrm{Mn}$ (TPP)Cl films are exposed to anions other than iodide, some anions can in fact interfere with the optical iodide response by competing as counter anions for the $\mathrm{Mn}(\mathrm{TPP})^{+}$ or $\mathrm{Mn}(\mathrm{TPP}) \mathrm{H}_{2} \mathrm{O}^{+}$sites in the film (see reactions 1-3 above). As stated in Table 1, salicylate and perchlorate anions alone caused very small absorbance changes, but their interfering effects are rather large when present together with iodide. This suggests that these species have high extraction coefficients into the $\mathrm{Mn}(\mathrm{TPP}) \mathrm{Cl}$ doped film. Such anions can be extracted either as axial lig- 
TABLE 1

Nomalized absorbance at $470 \mathrm{~nm}$ of the Mn(TPP)Cl film exposed to $1 \mathrm{mM}$ solution of iodide and interfering anions in $1: 1$ mole ratio ${ }^{\text {a }}$

\begin{tabular}{lll}
\hline Anion & \multicolumn{2}{l}{ Background solution } \\
\cline { 2 - 3 } & $\mathrm{NaH}_{2} \mathrm{PO}_{4}{ }^{\mathrm{b}}$ & $\mathrm{H}_{2} \mathrm{O}$ \\
\hline none & 1.00 & 1.00 \\
$\mathrm{I}^{-}$ & 0.33 & 0.49 \\
$\mathrm{I}^{-}+\mathrm{Sal}^{-}$ & 0.50 & 0.72 \\
$\mathrm{I}^{-}+\mathrm{SCN}^{-}$ & 0.25 & 0.38 \\
$\mathrm{I}^{-}+\mathrm{NO}_{2}^{-}$ & 0.45 & 0.60 \\
$\mathrm{I}^{-}+\mathrm{ClO}_{4}^{-}$ & 0.42 & 0.56 \\
$\mathrm{I}^{-}+\mathrm{Br}^{-}$ & 0.31 & 0.48 \\
$\mathrm{I}^{-}+\mathrm{NO}_{3}^{-}$ & 0.34 & 0.52 \\
$\mathrm{I}^{-}+\mathrm{Cl}^{-}$ & 0.35 & 0.52 \\
$\mathrm{I}^{-}+\mathrm{OAc}^{-}$ & 0.36 & 0.53 \\
\hline
\end{tabular}

${ }^{\mathrm{a}}$ Film composition: $\mathrm{Mn}(\mathrm{TPP}) \mathrm{Cl}, \mathrm{DOS}, \mathrm{PVC} .{ }^{\mathrm{b}} \mathrm{pH} 4.2$.

ands (reactions 1 and 2), or as counter anions to the solvent ligated $\mathrm{Mn}(\mathrm{TPP}) \mathrm{H}_{2} \mathrm{O}^{+}$species (reaction 3). In either case, these reactions will compete with iodide as the preferred counter anion in the film. Since only the presence of thiocyanate yields positive errors, it is likely that thiocyanate coordinates directly and strongly to $\mathrm{Mn}(\mathrm{TPP})^{+}$, also altering the electronic structure of the central $\mathrm{Mn}^{3+}$ ion. On the other hand, negative interferences from salicylate and perchlorate appear to be due to the large partition coefficients of these species into the polymer film as competing dissociated (non-ligated) counter anions to $\mathrm{Mn}$ (TPP) $\mathrm{H}_{2} \mathrm{O}^{+}$.

The optical response of the Mn(TPP)-doped films to iodide ion is also highly dependent on the concentration of the counter anion $\mathrm{X}^{-}$in the sample (i.e., $X_{(a q)}^{-}$in Eqns. 1-3). In practice this concentration should be fixed to define a conditional equilibrium constant for the ion-exchange reaction. In buffered sample solutions it appears that $\mathrm{X}^{-}$is predominately hydroxide ion and hence, the $\mathrm{pH}$ of the sample will control the ion-exchange of $\mathrm{I}^{-}$into the film. Indeed as shown in Fig. $3 b$, the sensitivity to iodide is decreased as the solution $\mathrm{pH}$ is increased. This is consistent with previous results obtained in the potentiometric measurement mode [21]. Both the potentiometric and optical data suggest that an increase in the $\mathrm{pH}$ of the sample solution causes deprotonation of the weakly coordinated water, yielding a very strong hydroxide ion ligand coordinated to the central Mn(III) [i.e., Mn(TPP)OH]. Thus, as with the potentiometric system, optical anion sensing based on Mn(III) porphyrins will require that the sample solution be buffered at a $\mathrm{pH}<5.5$.

\section{Anion selectivities of polymer films doped with $\operatorname{In}(\mathrm{OEP}) \mathrm{Cl}$ and $\mathrm{pH}$ indicators}

As mentioned above, the direct optical response of polymer films doped with In(OEP)Cl alone to various anions is very small. However, based on earlier membrane electrode potentiometric selectivity data, it appears that In(OEP) within polymeric films interacts quite strongly with chloride and nitrite [23,27]. To take advantage of this fact for optical sensing of these species, a pH indicator (IndH) was incorporated into the film to enhance the optical absorbance change. In this sensing mode (see Fig. 2b), selective extraction of anions $\left(\mathrm{Y}^{-}\right)$by $\operatorname{In}(\mathrm{OEP})^{+}$will be accompanied by the co-extraction of a proton (to maintain charge neutrality in the film), and concomitant protonation of the added pH chromophore yielding a large change in the optical absorbance of the film. This process can be described by Eqns. 4 or 5 (depending on whether the anionic form of the indicator can actually ligate to the In(III) center of the porphyrin):

$$
\begin{gathered}
\operatorname{In}(\text { OEP })_{(\mathrm{m})}^{+}+\text {Ind }_{(\mathrm{m})}^{-}+\mathrm{HY}_{(\mathrm{aq})} \rightleftharpoons \\
\operatorname{In}(\mathrm{OEP}) \mathrm{Y}_{(\mathrm{m})}+\operatorname{IndH}_{(\mathrm{m})}
\end{gathered}
$$

or

$$
\begin{gathered}
\operatorname{In}(\text { OEP }) \text { Ind }_{(\mathrm{m})}+\mathrm{HY}_{(\mathrm{aq})} \\
\operatorname{In}(\mathrm{OEP}) \mathrm{Y}_{(\mathrm{m})}+\operatorname{IndH}_{(\mathrm{m})}
\end{gathered}
$$

where $\mathrm{Y}^{-}$is the anion being sensed. By using $\alpha$ to represent the fraction of total indicator $\left(\operatorname{Ind}_{T}\right)$ in the deprotonated form ([Ind $\left.{ }^{-}\right]$), $\alpha$ can be related to the absorbance values at a given wavelength as follows:

$\alpha=\left(A-A_{0}\right) /\left(A_{1}-A_{0}\right)=\left[\right.$ Ind $\left.^{-}\right] /\left[\right.$Ind $\left._{\mathrm{T}}\right]$

where $A_{0}$ and $A_{1}$ correspond to the absorbance of the completely protonated and deprotonated pH indicator, respectively. In the case when the 


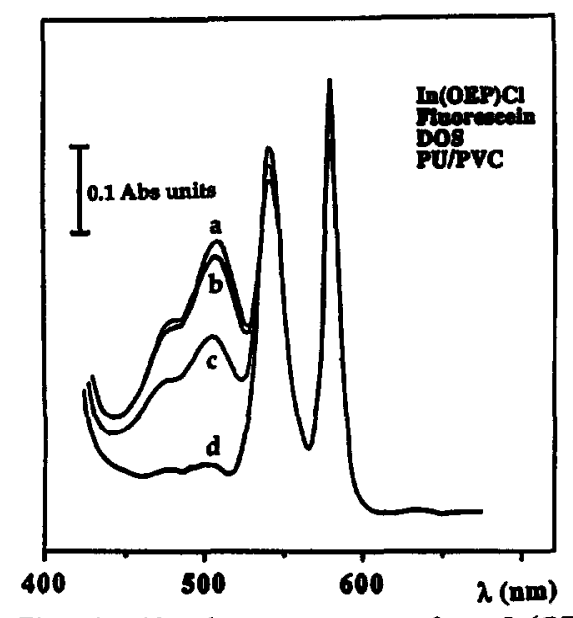

Fig. 4. Absorbance spectra of a $\operatorname{In}(\mathrm{OEP}) \mathrm{Cl} / \mathrm{Fl} / \mathrm{PU} /$ PVC/DOS film at varying chloride concentrations; (a) 0.0 , (b) $1 \times 10^{-5} \mathrm{M}$, (c) $1 \times 10^{-4} \mathrm{M}$ and (d) $10^{-3} \mathrm{M}$ (at pH 4.2).

porphyrin carrier and indicator are in a $1: 1$ ratio within the film, the relationship between relative absorbance $(\alpha)$, the equilibrium constant for reaction 4 or $5\left(K_{e 4}\right)$, the activities of protons and anions in the sample solution, and the optical selectivity coefficient $K_{\mathrm{i}, \mathrm{j}}^{\mathrm{opt}}$ ( $K_{\mathrm{i}, \mathrm{j}}^{\mathrm{opt}}$ is defined by analogy to that for ion-selective electrodes $[7,8,28]$ can be expressed by Eqn. 7:

$\left(1-\alpha^{2}\right) / \alpha^{2}=K_{\text {eq }} a_{\mathrm{H}^{+}}\left(a_{\mathrm{X}^{-}}+K_{\mathrm{i}, \mathrm{j}}^{\mathrm{opt}} a_{\mathrm{j}}\right)$

Fluorescein was initially examined as the $\mathrm{pH}$ indicator within PVC and PVC/PU films. Polymer films containing fluorescein and $\operatorname{In}(\mathrm{OEP}) \mathrm{Cl}$ in a mole ratio of $1: 1$, change color from orange to red upon exposure to solutions containing chloride when the sample is at $\mathrm{pH}<5$. As shown in Fig. 4, there is a large absorption change in the range of $430-520 \mathrm{~nm}$ due to protonation of fluorescein, and a slight increase in the absorbance of the film at 540 and $576 \mathrm{~nm}$ owing to the binding (ligation) of chloride to the indium(III) of the porphyrin complex. Since the absorption $\lambda_{\max }$ for fluorescein does not change when the $\operatorname{In}(\mathrm{OEP}) \mathrm{Cl}$ ionophore is added to the film, it appears that the deprotonated fluorescein does not coordinate directly to indium (III), but rather serves as a dissociated counter anion (see Eqn. 4) to In(OEP) ${ }^{+}$. This is in contrast to when ETH 2412 is used as the $\mathrm{pH}$ indicator within the film (see below).

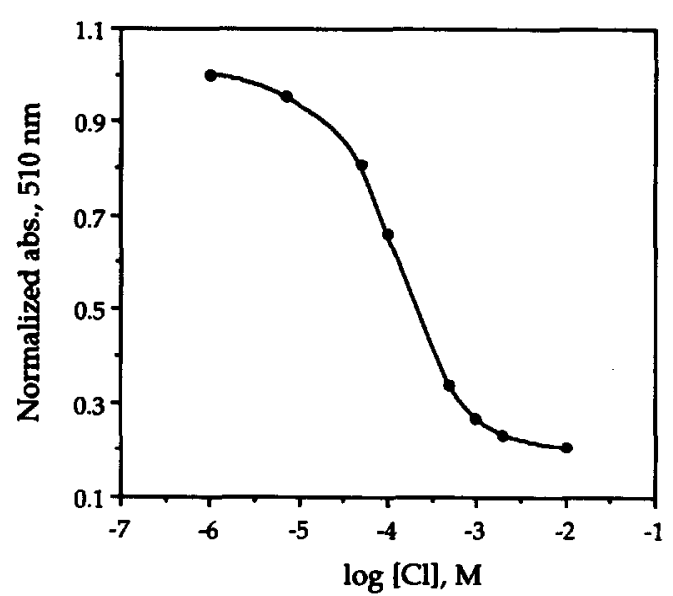

Fig. 5. Normalized absorbances of $\operatorname{In}(\mathrm{OEP}) \mathrm{Cl} / \mathrm{Fl}$ doped film at $510 \mathrm{~nm}$ as a function of $\log [\mathrm{Cl}]$. Film composition is as in Fig. 4. (pH 4.2.)

The normalized optical response curve (absorbance at $510 \mathrm{~nm}$ ) for chloride using fluorescein and $\mathrm{In}(\mathrm{OEP}) \mathrm{Cl}$ in a PU/PVC film at $\mathrm{pH}$ 4.20 is shown in Fig. 5. The dynamic range of response toward chloride is $10^{-5}$ to $10^{-3} \mathrm{M}$. The selectivity order follows: $\mathrm{Sal}^{-}>\mathrm{I}^{-} \sim \mathrm{Br}^{-} \sim \mathrm{NO}_{2}^{-}$ $\sim \mathrm{Cl}^{-} \gg \mathrm{SCN}^{-}>\mathrm{ClO}_{4}^{-}>\mathrm{NO}_{3}^{-}>\mathrm{H}_{2} \mathrm{PO}_{4}^{-}$(see Table 2). This selectivity sequence is consistent with that observed in potentiometric studies using In(OEP)Cl doped PVC membranes [23,27], and illustrates a much greater response to chloride

TABLE 2

Anion selectivity coefficients of various optical films ${ }^{\text {a,b }}$

\begin{tabular}{|c|c|c|c|}
\hline \multirow[t]{2}{*}{ Anions } & \multicolumn{3}{|l|}{$\log K_{\mathrm{C}_{\mathrm{j}}}^{\mathrm{opt}}$} \\
\hline & $\begin{array}{l}\operatorname{In}(\mathrm{OEP}) \\
\text { fluorescein }\end{array}$ & $\begin{array}{l}\text { In(OEP)Cl } \\
\text { ETH } 2412^{c}\end{array}$ & $\begin{array}{l}\text { MTDDACl } \\
\text { ETH } 2412^{\text {d }}\end{array}$ \\
\hline $\mathrm{Cl}^{-}$ & 0 & 0 & 0 \\
\hline $\mathrm{Sal}^{-}$ & 0.6 & 0.7 & 2.6 \\
\hline $\mathbf{I}^{-}$ & 0.3 & 0.2 & 2.8 \\
\hline $\mathrm{Br}^{-}$ & 0.2 & 0.1 & 1.4 \\
\hline $\mathrm{NO}_{2}^{-}$ & 0.3 & 0.2 & 0.5 \\
\hline $\mathrm{SCN}^{-}$ & -1.4 & -1.8 & 2.9 \\
\hline $\mathrm{ClO}_{4}^{-}$ & -2.0 & -2.2 & 3.4 \\
\hline $\mathrm{NO}_{3}^{-}$ & -2.9 & -2.8 & 1.4 \\
\hline $\mathrm{OAc}^{-}$ & -2.0 & -2.2 & - \\
\hline $\mathrm{H}_{2} \mathrm{PO}_{4}^{2-}$ & $<-3.5$ & $<-3.5$ & $<-1.0$ \\
\hline
\end{tabular}

a Film compositions: $\mathrm{pH}$ indicator, carrier in o-NPOE, $\mathrm{PU} / \mathrm{PVC}$ matrix. ${ }^{\mathrm{b}} \mathrm{K}_{\mathrm{C}, \mathrm{j}}^{\mathrm{cos}}$ is calculated at $\alpha=0.5$. ${ }^{\mathrm{c}}$ measurement at pH 4.2. ${ }^{d}$ measurement at $\mathrm{pH} 7.2$. 
than that which can be achieved using quaternary ammonium ion exchangers as membrane components (see Table 2 and Refs. 14, 15).

The response times for the fluorescein/In (OEP)Cl films were typically 2-3 min for $5 \mu \mathrm{m}$ films (Fig. 6). By reducing the membrane thickness to $3 \mu \mathrm{m}$, response times of less than $2 \mathrm{~min}$ could be readily achieved. However, because of gradual leaching of fluorescein into the aqueous test solutions, the life-time of anion sensing films prepared with fluorescein are relatively short. This leach rate, and thus sensor lifetime, depends on the $\mathrm{pH}$ of the sample solution. At sample $\mathrm{pH}$ $>5.0$, the leach rate was found to be fast, with optical anion response lasting for only $1-2 \mathrm{~h}$; in contrast, at pH 4.2, optical anion response could be achieved for a period of one week.

To overcome this leaching problem, a more lipophilic pH chromophore, ETH 2412, was investigated. ETH 2412 has been used previously as an indicator for polymer film type anion optical sensors based on methyltridodecylammonium (MTDDA) sites [14]. In this earlier work, a large absorbance change at $540 \mathrm{~nm}$ was used for sensing purposes. Figure 7 illustrates the change in the absorption spectra of ETH 2412/In(OEP)Cl films when exposed to test solutions containing increasing levels of the chloride. Note, that the changes in the spectrum occur at $460-510 \mathrm{~nm}$, not $540 \mathrm{~nm}$ as had been observed when this indicator was used with MTDDA [14]. The fact that the $\lambda_{\max }$ for ETH 2412 is shifted when

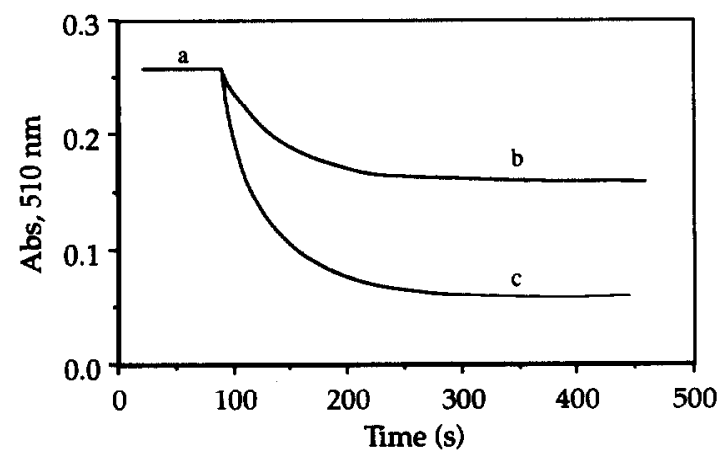

Fig. 6. Dynamic optical response of a $\operatorname{In}(\mathrm{OEP}) \mathrm{Cl} / \mathrm{Fl}$ doped film at $510 \mathrm{~nm}$ to changes in chloride concentration at $\mathrm{pH}$ 4.2: (a) $1 \times 1^{-5} \mathrm{M}$; (b) $1 \times 10^{-4} \mathrm{M}$; and (c) $10^{-3} \mathrm{M}$. Film composition is as in Fig. 4.

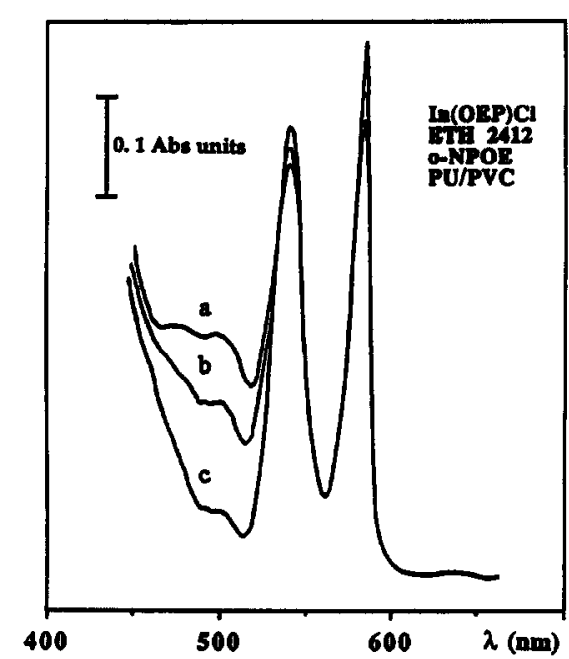

Fig. 7. Absorption spectra of In(OEP)Cl/ETH 2412/PU/ PVC/o-NPOE film for chloride concentrations of (a) 0.0 , (b) $1 \times 10^{-4} \mathrm{M}$ and (c) $10^{-3} \mathrm{M}$. (pH 4.2.)

In(OEP)Cl is present in the film suggests that, unlike fluorescein above, a direct ligation occurs between ETH 2412 and $\operatorname{In}(\mathrm{OEP})^{+}$(reaction 5 above). Considering the structure of ETH 2412 (see the structure below), this interaction likely involves the coordination of the nitro or hydroxy group of ETH 2412 to In(III). Despite this direct interaction, the presence of chloride and other anions in the test solution can compete effectively for the metal ion coordination site, yielding protonation of a non-coordinated indicator.

The normalized absorbance changes at $500 \mathrm{~nm}$ as a function of the logarithm of salicylate, chloride, nitrite, perchlorate and nitrate concentration for In(OEP)Cl/ETH 2412 in PU/PVC films are shown in Fig. 8. The resulting optical anion selectivity coefficients are summarized in Table 2. Again, this data shows clearly that In(OEP)Cl doped films respond in a non-Hofmeister pattern, with preference for $\mathrm{Sal}^{-}, \mathrm{I}^{-}, \mathrm{Br}^{-}, \mathrm{NO}_{2}^{-}$, and $\mathrm{Cl}^{-}$ over more lipophilic $\mathrm{SCN}^{-}$and $\mathrm{ClO}_{4}^{-}$anions. This is precisely the pattern observed with fluorescein (above) as the $\mathrm{pH}$ indicator within the film. This unique optical selectivity pattern for In(OEP)Cl doped films regardless of $\mathrm{pH}$ indicator used, is believed to be due to the specific interactions of given anions as axial ligands with the In(III) center. Thus, enchanced selectivity for 


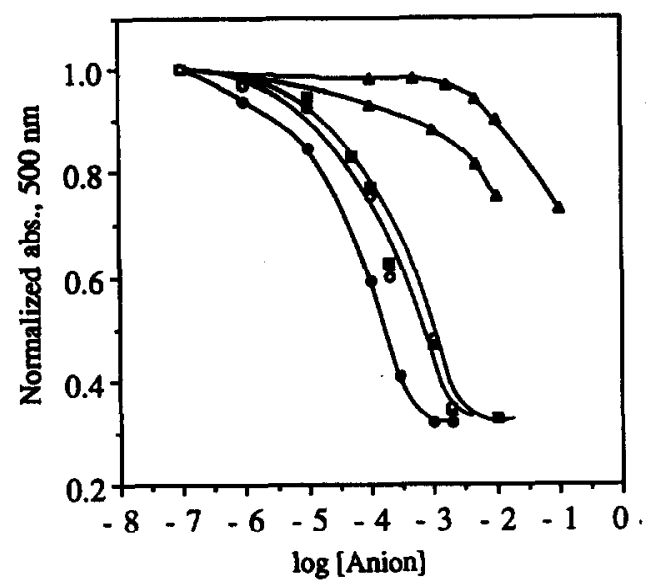

Fig. 8. Normalized absorbances of In(OEP)Cl/ETH $2412 / \mathrm{PU} / \mathrm{PVC} / 0 . \mathrm{NPOE}$ film at $500 \mathrm{~nm}$ for different anions. (ム) $\mathrm{NO}_{3}^{-},(\Delta) \mathrm{ClO}_{4}^{-},(\boldsymbol{\square}) \mathrm{Cl}^{-},(0) \mathrm{NO}_{2}^{-},(\bullet) \mathrm{Sal}^{-}$. (pH 4.2.)

strongly ligated anions (e.g., $\mathrm{Cl}^{-}, \mathrm{NO}_{2}^{-}$, etc.) over some very lipophilic yet weakly coordinating anions (e.g., $\mathrm{ClO}_{4}^{-}, \mathrm{SCN}^{-}$) is observed.

\section{Conclusions}

This work demonstrates the concept of using metalloporphyrins as active film components in the design of reversible anion-selective optical sensors. As has been observed previously in potentiometric polymer membrane type ion-selective electrode configurations, the use of metalloporphyrins for optical anion sensing yields films with selectivities which differ substantially from the classical Hofmeister pattern. Two modes of transduction have been identified to achieve reversible optical anion response. As shown, $\mathrm{Mn}$ (TPP)Cl can be used alone within films as a chromoionophore for the detection of iodide, while In(OEP)Cl can be employed as an anion carrier in combination with a proton sensitive dye. Although the anion selectivities of the $\mathrm{Mn}$ (TPP)Cl and In(OEP)Cl based optical sensing films described here may not be adequate for many anion sensing applications, it is likely that the concept demonstrated here could be applied with other more selective metalloporphyrin or different metal-ligand complexes to yield optical anion sensors with selectivities more suitable for practical analytical applications. Indeed, based on previous potentiometric data, the use of a sterically hindered Mn(III) porphyrin [21], a Sn(IV) tetraphenylporphyrin, or a $\mathbf{H g}$ (II)-diethyldithocarbamate complex along with suitable $\mathrm{pH}$ indicators within thin polymeric films, should yield highly selective optical sensors for thiocyanate, salicylate, and sulfite, respectively. Such studies are currently in progress.

We gratefully acknowledge the National Institutes of Health (GM 28882) for supporting this work.

\section{REFERENCES}

1 J. Janata, Anal. Chem., 62 (1990) 33R.

2 O.S. Wolfbeis, Fresenius" J. Anal. Chem., 337 (1990) 522.

3 L.A. Saari and W.R. Seitz, Anal. Chem., 55 (1983) 667.

4 Z. Zhujun and W.R. Seitz, Anal. Chim. Acta, 171 (1985) 251.

5 J.I. Peterson, S.R. Goldstein, R.V. Fitzgerald and D.K. Buckhold, Anal. Chem., 52 (1980) 864.

6 H.E. Posch, M.J.P. Leiner and O.S. Wolfbeis, Fresenius' J. Anal. Chem., 334 (1989) 162.

7 W.E. Morf, K. Seiler, B. Lehmann, Ch. Behringer, S.S.S. Tan, K. Hartman, P.R. Sorensen and W. Simon, in E. Pungor (Ed), Ion-Selective Electrodes, Vol. 5, Akademiai Kiado, Budapest, 1989, p. 115.

8 W.E. Morf, K. Seiler, P.R. Sorensen and W. Simon, in E. Pungor (Ed), Ion-Selective Electrodes, Vol. 5, Akademiai Kiado, Budapest, 1989, p. 141.

9 K. Seiler, W.E. Morf, B. Rusterholz and W. Simon, Anal. Sci., 5 (1989) 557.

10 W.E. Morf, K. Seiler, B. Rusterholz and W. Simon, Anal. Chem., 62 (1990) 738.

11 K. Wang, K. Seiler, W.E. Morf, U.E. Spichiger, W. Simon, E. Lindner and E. Pungor, Anal. Sci., 6 (1990) 715.

12 K. Seiler, K. Wang, E. Bakker, W.E. Morf, B. Rusterholz, U.E. Spichiger and W. Simon, Clin. Chem., 37 (1991) 1350.

13 M. Lerchi, E. Bakker, B. Rusterholz and W. Simon, Anal. Chem., 64 (1992) 1534.

14 S.S.S. Tan, P.C. Hauser, N.A. Chaniotakis, G. Suter and W. Simon, Chimia, 43 (1989) 257

15 S.S.S. Tan, P.C. Hauser, K. Wang, K. Fluri, K. Seiler. B. Rusterholz, G. Suter, M. Kruettli, U.E. Spichiger and W. Simon, Anal. Chim. Acta, 225 (1991) 35.

$16 \mathrm{Ch}$. Behringer, B. Lehman and W. Simon, Chimia, 41 (1987) 397.

17 E. Urbano, H. Offenbacher and O.S. Wolfbeis, Anal. Chem., 56 (1984) 427.

18 W.A. Wyatt, F.V. Bright and G.M. Hieftje, Anal. Chem., 59 (1987) 2272. 
19 M.K. Freeman and L.G. Bachas, Anal. Chim. Acta, 241 (1990) 119.

20 M.K. Freeman and L.G. Bachas, Anal. Chim. Acta, 256 (1991) 269.

21 N.A. Chaniotakis, S.B. Park, A.M. Chasser, M.E. Meyerhoff and J.T. Groves, Anal. Chem., 60 (1988) 188.

22 N.A. Chaniotakis, S.B. Park and M.E. Meyerhoff, Anal. Chem., 60 (1989) 566.

23 S.B. Park, W. Matuszewski, M.E. Meyerhoff, Y.H. Liu and K.M. Kadish, Electroanalysis, 3 (1991) 909.
24 J. Buchler, in D. Dolphin (Ed.), The Porphyrins, Academic Press, New York, 1978, Chap. 6.

25 M. Bhatti, W. Bhatti and E. Mast, Inorg. Nucl. Chem. Lett., 8 (1972) 133.

26 O. Dinten, U.E. Spichiger, N. Chaniotakis, P. Gehrig, B. Rusterholz, W.E. Morf and W. Simon, Anal. Chem., 63 (1991) 596.

27 E. Wang, R. Schillar and M.E. Meyerhoff, unpublished results.

28 E. Bakker and W. Simon, Anal. Chem., 64 (1992) 1805. 